\title{
How can community engagement in health research be strengthened for infectious disease outbreaks in Sub-Saharan Africa? A scoping review of the literature
}

Samantha Vanderslott ${ }^{1 *}$ (D, Manya Van Ryneveld ${ }^{2}$, Mark Marchant ${ }^{3}$, Shelley Lees ${ }^{3}$, Sylvie Kwedi Nolna ${ }^{4}$ and Vicki Marsh $5,6,7$

\begin{abstract}
Background: Community engagement (CE) is a well-established practical and scholarly field, recognised as core to the science and ethics of health research, for which researchers and practitioners have increasingly asked questions about desired standards and evaluation. In infectious disease outbreak contexts, questions may be more complex. However, it is unclear what body of knowledge has been developed for CE specifically as it applies to emerging infectious diseases. This scoping review seeks to describe (1) How CE has been conceptualised and understood; and (2) What conclusions have research teams reached on the effectiveness of CE in these settings, including challenges and facilitators.
\end{abstract}

Methods: We used a scoping review framework by Arksey and O'Malley (Int J Soc Res Methodol 8:19-32, 2005) to structure our review. We conducted a brainstorming session and initial trial search to inform the protocol, search terms, and strategy. Three researchers discussed, developed and applied agreed screening tools and selection criteria to the final search results. Five researchers used the screening tools to screen abstracts and full text for inclusion by consensus. Additional publications were sought from references of retrieved publications and an expert call for literature. We analysed and reported emerging themes qualitatively.

Results: We included 59 papers from a total of 722 articles derived from our trial and final literature searches, as well as a process of "citation chasing" and an expert call for grey literature. The core material related exclusively to health research trials during the 2014-2016 West Africa Ebola outbreak. We synthesized reports on components of effectiveness of CE to identify and propose three themes as essential elements of effective CE.

* Correspondence: samantha.vanderslott@paediatrics.ox.ac.uk

'Oxford Vaccine Group \& Oxford Martin School, University of Oxford, 34 Broad St, Oxford OX1 2BD, UK

Full list of author information is available at the end of the article

(c) The Author(s). 2021 Open Access This article is licensed under a Creative Commons Attribution 4.0 International License, which permits use, sharing, adaptation, distribution and reproduction in any medium or format, as long as you give appropriate credit to the original author(s) and the source, provide a link to the Creative Commons licence, and indicate if changes were made. The images or other third party material in this article are included in the article's Creative Commons licence, unless indicated otherwise in a credit line to the material. If material is not included in the article's Creative Commons licence and your intended use is not permitted by statutory regulation or exceeds the permitted use, you will need to obtain permission directly from the copyright holder. To view a copy of this licence, visit http://creativecommons.org/licenses/by/4.0/ The Creative Commons Public Domain Dedication waiver (http://creativecommons.org/publicdomain/zero/1.0/) applies to the data made available in this article, unless otherwise stated in a credit line to the data. 


\begin{abstract}
(Continued from previous page)
Conclusions: While there is a large volume of literature documenting CE activities in infectious disease research settings generally, there are few accounts of effectiveness dimensions of CE. Our review proposes three themes to facilitate the effectiveness of CE initiatives as essential elements of CE activities in infectious diseases studies: (1) Communication towards building collaborative relationships; (2) Producing contextual knowledge; and (3) Learning lessons over time. As there were relatively few in-depth accounts of CE from our literature review, documentation and accounts of CE used in health research should be prioritised.
\end{abstract}

Keywords: Community engagement, Effectiveness, Health research, Epidemics, Outbreaks, Infectious disease, SubSaharan Africa

\section{Background}

$\mathrm{CE}$ has become an ethical requirement for research involving human participants [52]. Dickert and Sugarman [19] have identified four ethical goals of CE: enhancing protection, enhancing benefits, creating legitimacy, and sharing responsibility. In the 2000s, there were significant developments in CE in clinical trials in SubSaharan Africa, especially human immunodeficiency virus (HIV) trials. These changes were motivated by the early closure of pre-exposure prophylaxis (PrEP) trials in Cambodia and Cameroon following protests led by HIV activists who argued trial participants were taking risks but not receiving enough benefits [41]. In response, activists called for a strengthened role of communities in the development and the conduct of HIV trials and pushed for a broader view of $\mathrm{CE}$ to promote community empowerment and shared decision-making [50]. Following these calls, there have been a number of successes in promoting dialogue with communities, especially the transformation from an activist-led movement that 'pushed' for inclusion, to a researcher-led effort, where study staff worked to encourage participation and 'pull' communities into relationships with researchers $[38,50]$. Although there have been positive developments in CE, there are concerns that $\mathrm{CE}$ in clinical trials does not always address the broader concerns of participants, governments, activists, and researchers themselves, especially political and economic issues related to involving people from resource poor communities [43].

With the growing number of clinical trials around emerging diseases in the last five years, there have been further calls for improved CE, especially in emergency situations. The 2014-16 Ebola Virus Disease (EVD) outbreak in West Africa led to the deaths of more than 11,000 people in Sierra Leone, Liberia and Guinea [57]. Experiences during the response to the epidemic revealed to a broader community of scientists the dangers of ineffective $\mathrm{CE}$, especially mistrust between communities and authorities [27]. In the wake of these experiences, a number of guidelines and reports were published for CE for clinical trials for emerging diseases [15].
The Good Participatory Practice Guidelines for Trials of Emerging (and Re-emerging) Pathogens (GPP-EP) [57] set out recommendations for stakeholder engagement that draw from an expert base of actors involved in the EVD outbreak, and borrow from biomedical HIV intervention 'good participatory practice' trial guidelines (e.g. [53]). The GPP-EP addresses key concepts in stakeholder engagement rather than community engagement, defining stakeholders, ethical issues, and the need for long-term, sustained partnerships. In this document, using the term 'stakeholder' rather than 'community' in discussing engagement as the focus implies a larger set of health research actors. Here 'synergy' between research and response is also seen as crucial to set out ethical principles and 'optimal practice' through nine activities throughout the research life-cycle [57]. The GPP-EP recommends processes to develop research protocols, budget allocation and time, and collaborative partnering for a "collective shaping of relevant, scientifically rigorous, ethical research that is in line with international standards, respects the rights of the involved population, contributes to and does not undermine the epidemic response, and leaves a sustaining legacy for the involved population" (ibid. p. 4). Effective engagement is both an intrinsic ethical imperative and has instrumental value toward enhancing trial conduct and contributing to robust research outcomes. While the window of opportunity for research during an outbreak is short, trial stakeholder identification and engagement is crucial. The foundational GPP-EP principles underpin partnerships with "respect, fairness, integrity, transparency, accountability, and autonomy, while the benchmarks include mutual understanding, complementarity, and efficiency" (ibid. p. 5).

In addition to the World Health Organization (WHO) report, an ad hoc committee was formed at the National Academies of Sciences, Engineering, and Medicine to review and conduct an analysis of the clinical trials conducted during the 2014-2016 EVD outbreak. Their consensus report explores and analyses the scientific and ethical issues related to clinical trial design, conduct, and reporting. The report's second chapter focuses on "Conducting clinical research during an epidemic" [34]. The 
core recommendations include: i) begin CE early (recognising contingency of health research and the public health response); ii) ensure that $\mathrm{CE}$ is 'meaningful' (that is, that experiences are comprehensively and transparently reported and utilised); and iii) maintain sustained funding and investment to develop relationships in inter-epidemic periods. The report recognises the key role of social scientists or anthropologists in learning about cultural, social, political and historical dynamics that could affect $\mathrm{CE}$ and research and emphasises promoting the voices of local experts, leaders and community liaison staff. From a practical perspective, the authors describe the need for communication to engage multiple stakeholders in multiple ways, and ensure information is accurately presented, including through translations.

Although these documents provide good guidance on $\mathrm{CE}$, there has been no scoping review of the conduct of $\mathrm{CE}$ in emerging disease treatment and prevention trials. At this stage, an assessment of methods for measuring the 'effectiveness' of CE would be useful to strengthen and broaden these approaches. However, the existing diversity of definitions and methods for evaluating $\mathrm{CE}$ activities may preclude such an effort [2]. For this reason, we have focused this scoping literature review on the practice of $\mathrm{CE}$ by aiming to answer two key questions: (1) How has CE been conceptualised and understood? (2) What conclusions have research teams reached on the effectiveness of $\mathrm{CE}$, including the challenges and facilitating factors described?

\section{Methods}

We used a scoping review methodological framework provided by Arksey and O'Malley [4] to structure our review focusing on papers that documented community engagement in health research on infectious diseases. The review stages included: literature search strategy, trial literature search, literature searching, and reference search from final search. We began with a brainstorming session to define the search parameters, including key terms, inclusion and exclusion criteria and appropriate Boolean operators. As some concepts in our questions were ambiguous or difficult to define, we compiled a comprehensive list of search term synonyms.

We then conducted an initial trial search to test our search strategy and make adjustments on one database, Scopus. The trial search used two limits: peer-reviewed papers published after 1990 in English, including all types of research studies (e.g. randomised controlled trials, cohort studies, surveys and qualitative studies). After our trial search we devised our protocol document and registered it on Prospero (CRD42018112501). The 'final' search was conducted across multiple databases.
We also searched through references of publications retrieved from our final search for additional publications. This was a process of 'backward' and 'forward' citation chasing of included articles [9] for additional follow up references, where we identified linked studies by checking bibliographies of included reviews and conducting citation searches of our core papers. Three researchers (MV, SV, and $\mathrm{VM}$ ) were responsible for discussing and applying the agreed screening tools and selection criteria to the final search results. Five researchers (MV, SV, MM, VM and SK) used the screening tools to screen abstracts and then full text of selected articles for inclusion by consensus. Finally, we analysed and reported on the emergent themes qualitatively.

An iterative process throughout each of the stages was to clarify key concepts - identifying the key concepts, debating their suitability to the context of health research for infectious disease outbreaks in Sub-Saharan Africa and producing a final list with related definitions. We concentrated on the accounts of $\mathrm{CE}$ in six clinical trials for which a substantial account of these activities is given. Our final list is outlined in detail in the next section.

\section{Key concepts}

In this review, 'health research' is taken to include all health-related biomedical research. 'Emerging (and reemerging) infectious disease outbreaks' are those for which there are few or no countermeasures to control the transmission [56]. These outbreaks may also be referred to as epidemics if they spread across geographic areas.

$\mathrm{CE}$ - 'Community engagement' - is a more ambiguous term that encompasses a number of assumptions. A central assumption in the reference to the 'community' is that there are uniform communities and that these are readily identifiable. Marsh et al. [38] acknowledge that there are challenges such as defining 'community' and addressing power differentials between researchers and communities. As Wilkinson et al. [58] describe, 'community' can also be a socio-political construct underpinned by complex hierarchies and politics. The form of 'community' often differs across different types of health research. For example, in treatment trials, participants are recruited from an (often narrow) patient base, while in vaccine trials participants may come from a broader community of residents in a given geographic area. There is also a lack of clarity between CE being an ethical requirement with intrinsic value (mutual respect) and practical requirement with instrumental value (making health research feasible, acceptable, and maximising benefits).

We refer to 'engagement' to include the time in anticipation of (before), during and after outbreaks (including 
future considerations) and across all forms of 'engagement' or interaction. At the same time, we recognise that 'engagement' is also a contested term and encompasses many activities with varying goals [9]. Sherry Arnstein's 'Ladder of participation' [5] is a popular representation of the different levels of citizen involvement from a situation of manipulation of citizens through categories of non-participation, to tokenism, to citizen power, towards an open society of cooperation. The form of engagement is often contingent on research methods, though this is rarely explicit [37]. A highly visible, large-scale clinical trial may necessitate more robust $\mathrm{CE}$ that puts at least some community members or trial participants in decision making roles alongside researchers. This type of engagement might be said to democratise a research endeavour that might otherwise risk being coercive or invasive. This legitimisation of research institutions and practices is no less important during epidemics, but it is likely to be more challenging operationally for two main reasons. First, many institutions' relationships and practices are more fluid during outbreaks, and therefore less predictable and more difficult to operate in. Second, any CE for research in outbreaks is likely to be conducted alongside engagement for the public health response.

Good practice in CE that achieves its aims is often described in terms of 'effectiveness', though there are other terms used (e.g. strength, quality, and impact) [17]. To assess whether CE has been effective, the goals of engagement need to be clear. In practice, $\mathrm{CE}$ activities can have multiple aims that are sometimes conflicting, and approaches to measuring achievement of these will be similarly complex [42]. Given the contestations around aims of $\mathrm{CE}$ and what constitutes good practice, we employ the 'broad tent' World Health Organization (WHO) definition: "a process of developing relationships that enable stakeholders to work together to address healthrelated issues and promote well-being to achieve positive health impact and outcomes" ([59], p. 12).

\section{Critical appraisal, coding and synthesis under themes}

We used three guidelines for quality appraisal. These guidelines were the 'Critical Appraisal Skills Programme' (CASP) systematic review checklist [16], the 'Confidence in the Evidence from Reviews of Qualitative research' (CERqual) approach [36] to determine robustness of results and the Authority, Accuracy, Coverage, Objectivity, Date, Significance (AACODS) checklist for critical evaluation of the grey literature [35].

We draw on our findings to offer an analysis of major elements of $\mathrm{CE}$ that are central to 'effectiveness' or good practice in research through the development of three core themes. We arrived at the themes during the analysis phase, during which we sorted all the sources into categories beginning with disciplinary approaches and general topic areas to be refined and reordered into themes based on the objectives and outcomes of CE. During this iterative process, we discussed the contents of each paper, condensing what we had assessed and through these discussions derived themes, which were continually refined. See Additional file 1 for the underlying conceptual framework of the three core themes for effective CE.

\section{Results}

The total number of papers identified through database searching was 460 . In addition, the trial search returned 203 papers, which were screened for relevance based on abstracts and titles (there were no duplicates as this search was only run on one database). We found 17 articles relevant to our question. After examining the overall relevance of our trial search results and consulting a librarian and experts in this field, we adapted search terms slightly before moving onto the final search. However, 14 'missing' articles from the initial trial search, which we had deemed as relevant to our questions based on their title or abstract but which did not appear in the final search due to the changes in search terms, were included (the remaining three articles that we had deemed relevant did appear in the new search and thus were not included as these would have been duplicates). The total number after duplicate articles were removed was 470 .

We screened these 470 titles and abstracts and excluded 412, leading us to a total of 58 articles for full text screening. Five people were involved in the full text screening of 58 articles, at which point a further 12 articles were excluded. In total the articles excluded on title and abstract screening were 412 . The full text screening was conducted using a standardised screening template with the characteristics outlined above, for which we also noted whether the paper was included and any follow-up references. From the full text screening, we generated a list of 50 follow-up references, through 'citation chasing'. We also made a call for literature at the African coaLition for Epidemic Research, Response and Training (ALERRT) consortium annual general meeting held in March 2019 in Dakar, Senegal, based largely on recommendations received by collaborators from the consortium as well as pieces encountered during searching and screening. This resulted in 9 pieces of grey literature being collected from the recommendations of experts.

Of this additional literature (grey and follow up references) a total of 46 articles were excluded. The main reason for excluding grey literature and citation chasing sources was the content not being substantive enough. MV, SV and VM met regularly to discuss screening choices and approaches to synthesis and analysis. At the final stage a total of 59 articles were included for analysis in the review. 


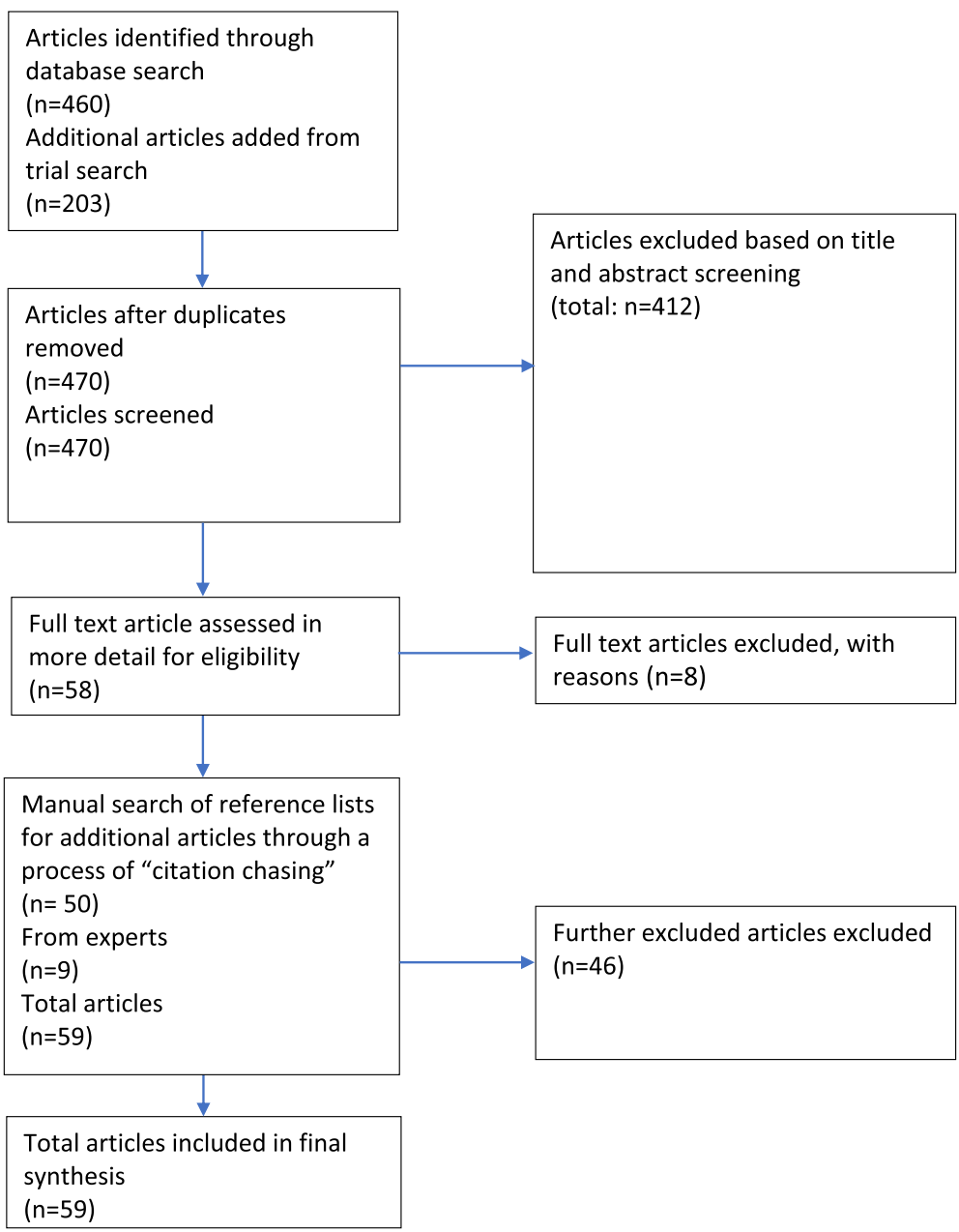

Fig. 1 PRISMA diagram

\section{Accounts of CE in the literature}

In the following section, we describe the $\mathrm{CE}$ activities undertaken in six clinical trials, what was described as 'working' or not, why, and any lessons suggested. We then describe the scope covered by a wider relevant literature on $\mathrm{CE}$, including research accounts that reference $C E$ activities and commentaries and analyses of what constitutes good practice for CE. Drawing on our findings, we offer an analysis of major elements of CE that are central to 'effectiveness' or good practice in research. We then go on to present three themes that summarise the conceptualisation and understandings of $\mathrm{CE}$ and the conclusions research teams reached on the effectiveness of $\mathrm{CE}$ in their settings.

Our final search across the electronic databases EBSCOhost, OVID, Proquest, Pubmed, Scopus and Web of Science returned 460 results. (See Additional file 2. for full search terms.) After deduplication using the reference software Mendeley, this was reduced to 267 . Two of the authors (MV and SV, with oversight from VM) conducted a title and abstract screening round, which left articles marked as 'yes' (include), 'flagged for interest' or 'unsure'. There were also 14 non-duplicated references from our initial trial search that we had flagged as relevant but did not come up in our main search due to changes in search terms. These were added manually to our spreadsheet of references for full text screening. We then extracted data using the characteristics in Table 1 below.

The Reporting Items for Systematic Reviews and Meta-Analyses (PRISMA) diagram in Fig. 1 above outlines our methodological process (see Additional file 3 for PRISMA Checklist).

\section{Empirical research (trials) with substantial CE accounts}

Papers on CE activities for Ebola treatment and prevention trials in Sierra Leone, Liberia and Guinea were the most substantial accounts of CE. These were either vaccine trials (four), which mostly recruited healthy volunteers from a wide community base, or treatment trials 
Table 1 Characteristics for data extraction

Context descriptors
Aims/objectives
Research type/topic
Community organisers
Community organising actions and mechanisms of engagement
Tools/medium
Community target/definition
Views on effectiveness/strengthening/quality/impact
Experience, success and lessons/learnings
Exiting

(two), which recruited in-patients during their stay in isolation facilities. The vaccine trials aimed to recruit healthy volunteers and had the strongest focus on $\mathrm{CE}$ as part of their recruitment strategy and associated need to engage with a wide area of local residents.

Table 2 below summarises the set-up, aims, and mechanisms of the CE strategy and activities, as reported in the literature linked to six trials conducted during the West Africa Ebola outbreak between 2014 and $2016 .{ }^{1}$ The trials varied in nature, size, design and in the scope of their reporting on $\mathrm{CE}$ aspects of their research. While all of the trials described CE to some degree - usually in relation to ethical principles such as those used in Good Clinical Research Practice - they used a variety of justifications, approaches and priorities as described later in this section. The difficulty in describing detail is that, from our review, it seems that CE for clinical trials is either (i) not generally written up as a research activity (for example, to evaluate progress towards goals) but as a process, or (ii) write-ups are not comprehensive, particularly where published papers are primarily reporting on trial activities and outcomes. For our analysis, therefore, we have gathered what is relevant and available from the literature.

\section{Other literature on CE during outbreaks: commentaries on and shorter references to $C E$}

In addition to reports of $\mathrm{CE}$ embedded in trials conducted during the 2014-16 EVD outbreak, across the trial-related literature there is a strong recognition of the importance of $\mathrm{CE}$ in facilitating the implementation

\footnotetext{
${ }^{1}$ One of these trials is still ongoing (the Ebovac Salone trial). The literature included in this section represents the results of our search and may not include very recently published articles even if related to these trials. The dominance of the 2014-2016 West Africa EVD outbreak is a striking characteristic of our overall search results, particularly given that we made an effort to keep our search terms as inclusive of all the major WHO blueprint diseases as possible. This suggests that there are significant gaps in the literature regarding $\mathrm{CE}$ for health research in other infectious disease outbreaks.
}

of health research. For example, Folayan et al. [30] identify four critical stakeholders and associated tasks that need to be implemented before clinical trials begin. These are: (1) Global research coordinating body (WHO); (2) Affected governments; (3) Ethics committees; and (4) Community Advisory Boards (CABs). The associated tasks centred around data-sharing and exploiting synergies, access and leverage of resources, reviewing/monitoring for ethical integrity, and working with ethics committees. Processes that clarified the roles and expectations of implementing partners for better $C E$ included the use of Standard Operating Procedures (SOPs) [46]. The use of SOPs was to provide national and district-level guidance, such as recruiting and training CE practitioners and how to structure social mobilisation or CE leadership alongside the rest of the response effort.

In this review, the value of $\mathrm{CE}$ is often framed in terms of encouraging support for the trial and the language used to describe this tends to be linked to promotion, enhancement and sensitisation [33, 47]. For example, the instrumental value of $\mathrm{CE}$ is recognised for overcoming challenges to both the outbreak research and the public health response, in addressing rumours and changing core risk behaviours, such as those around 'unsafe' burial practices [10] and in introducing new measures like contact tracing and quarantine [45].

In addition, one published report summarises the vaccination campaigns that were a major part of health research during the 2014-2016 EVD outbreak in West Africa. The Wellcome Trust and Center for Infectious Disease Research and Policy (CIDRAP) report "Recommendations for Accelerating the Development of Ebola Vaccines" [14] provides a review and analysis of the various aspects of research and development for Ebola vaccines, to provide an expert framework in the "global efforts to accelerate the availability of effective and safe Ebola vaccines" (ibid. p. 1). The report mostly focused on post-marketing Ebola vaccination campaigns, rather than trials or other health research activities. Despite the post-marketing framing, it still offers general CE recommendations that can be applied to health research. Consideration of early strategies for $\mathrm{CE}$ for vaccine deployment is included as well as descriptions of previous experiences where $C E$ played an important role in the successful rollout of vaccines. ${ }^{2}$ The treatment trials were not reported on as a group in this Wellcome and CIDRAP report. An example of the type of research conducted included testing the effectiveness of giving EVD

\footnotetext{
${ }^{2}$ Reversing resistance to polio vaccination in northern Nigeria, random selection for clinical trials of Malaria vaccines in Burkina Faso by using traditional games, and frequent, widespread and multi-layered communication strategies for the Meningitis Vaccine Project in Central Africa (ibid. p. 40-41).
} 
Table 2 Trial name, intervention, targeted recruitment population, reported CE strategy, activities, and outcomes

\begin{tabular}{|c|c|c|c|c|}
\hline Trial Name & Intervention & $\begin{array}{l}\text { Targeted recruitment } \\
\text { population }\end{array}$ & Reported CE strategy & Reported CE activities and outcomes \\
\hline & \multicolumn{4}{|c|}{ EBOLA VACCINE TRIALS $[20,34]$} \\
\hline $\begin{array}{l}\text { STRIVE } \\
\text { (completed) }\end{array}$ & $\begin{array}{l}\text { Vaccine trial } \\
\text { phase III; } \\
\text { individually } \\
\text { randomised, } \\
\text { open-label trial; } \\
\text { immediate vs }\end{array}$ & $\begin{array}{l}\text { Non-pregnant, frontline EVD } \\
\text { health workers or related } \\
\text { care workers across } 5 \\
\text { districts in Sierra Leone. }\end{array}$ & $\begin{array}{l}\text { Dedicated significant time and resources } \\
\text { for } C E \text {. This meant communication } \\
\text { beginning before trial launch (and } \\
\text { presentation to the full government/ } \\
\text { media). Communication continued post- } \\
\text { enrolment to support ongoing recruit- }\end{array}$ & $\begin{array}{l}\text { Communication activities included a } \\
24 \text {-hour hotline for questions. } \\
\text { Educational activities involved more than } \\
175 \text { sensitisation and information sessions } \\
\text { for potential participants, hospitals, } \\
\text { community health centres and ETUs. }\end{array}$ \\
\hline
\end{tabular}

deferred

vaccination;

8673

participants

enrolled.

\begin{tabular}{|c|c|c|}
\hline $\begin{array}{l}\text { Ebola ça } \\
\text { Suffit } \\
\text { (completed) }\end{array}$ & $\begin{array}{l}\text { Ring } \\
\text { vaccination; } \\
\text { novel cluster } \\
\text { RCT; } \\
\text { immediate vs } \\
\text { deferred } \\
\text { vaccination; } \\
7284 \\
\text { participants } \\
\text { enrolled. }\end{array}$ & $\begin{array}{l}\text { Index cases and their } \\
\text { contacts within an } \\
\text { epidemiologically informed } \\
\text { ring. }\end{array}$ \\
\hline $\begin{array}{l}\text { Ebovac } \\
\text { Salone } \\
\text { (ongoing) }\end{array}$ & $\begin{array}{l}\text { Vaccine trial } \\
\text { Phase III } \\
\text { (staged). }\end{array}$ & $\begin{array}{l}\text { Healthy volunteers, Sierra } \\
\text { Leone. }\end{array}$ \\
\hline
\end{tabular}

Social mobilisation began prior to any vaccination related activities taking place. Consent was gained from the main ring site where the vaccination took place, around the index patient's residence.
'Social mobilisation experts' to find cases and contacts who they sought to mobilise and gain consent for participation. Community leaders and representatives assisted in contacting patients where applicable. The experts explained the trial's objectives and implications of potential participation.
Iterative CE approach strongly informed by prior and ongoing qualitative research. 'Research-driven community engagement' seen as contributing to smooth recruitment and reducing disruption due to rumours and misinformation.

$\begin{array}{lll}\text { PREVAIL } & \text { Vaccine trial } & \text { Liberian residents aged } \\ \text { (completed) } & \text { phase II/III; } & >18 \text { years. } \\ & \text { randomised, } & \text { High risk communities } \\ \text { double-blind, } & \text { proximal and distal to an } \\ \text { placebo- } & \text { identified referral hospital in } \\ & \text { controlled trial; } & \text { Monrovia. } \\ & 1500 & \\ & \text { participants } & \\ & \text { enrolled. }\end{array}$

\section{EBOLA TREATMENT TRIALS [47]}

\begin{tabular}{|c|c|c|}
\hline $\begin{array}{l}\text { JIKI } \\
\text { (completed) }\end{array}$ & $\begin{array}{l}\text { Treatment trial } \\
\text { Phase II; } \\
\text { non- } \\
\text { comparative, } \\
\text { single-arm, } \\
\text { open-label clin- } \\
\text { ical trial. }\end{array}$ & $\begin{array}{l}\text { Any patient aged }>1 \text { year } \\
\text { with lab confirmed EVD; } \\
\text { four rural Ebola treatment } \\
\text { centers (ETCs) in Guinea. }\end{array}$ \\
\hline $\begin{array}{l}\text { Ebola Tx. } \\
\text { (completed) }\end{array}$ & $\begin{array}{l}\text { Treatment trial, } \\
\text { phase II/III. } \\
\text { Open-label, } \\
\text { nonrandomised } \\
\text { clinical trial. }\end{array}$ & $\begin{array}{l}\text { Donor mobilisation of EVD } \\
\text { survivors. } \\
\text { Lab-confirmed EVD patients }\end{array}$ \\
\hline
\end{tabular}

Social mobilisation strategy with four pillars: advocacy, communications, community engagement and monitoring and evaluation.

The trial organisers recognised the context of fear and mistrust of international actors. The main recruitment efforts were inside the four ETCs involved in the study. A CAB was set up and involved in discussions on trial protocol, CE approach and informed consent processes.

Strong focus on donor mobilisation and role of Survivors Association-motivation to donate linked to feelings of social responsibility as survivors.
Dedicated social science team and community liaison teams aimed to understand intra-community power dynamics. Conclusion that local understandings of fairness can inform the recruitment strategy design and rumours can be addressed through 'active dialogue' rather than on correcting misinformation. This emerging understanding was used to support and adapt CE over the course of the trial.

Activities included: Reaching out to community decision-makers, opinion leaders and political leaders for support and approval, targeted messaging, answering FAQs, print and broadcast media communication, distributing flyers, jingles and songs on television and radio, text message communications with telecommunication companies' subscribers etc.

A pretrial initiative was used to inform and involve community leaders, and develop 'thoughtful, culturally appropriate messages' and a consensual community strategy.

The trial was conducted in partnership with public health response NGOs.

Issues identified were the stigma and perceptions of health impacts of donating blood - a decrease in vital strength and antibodies, fears of loss of acquired protection against EVD. survivor plasma to patients, where the CE activities included outreach to EVD survivors to request plasma donation.

All of these trials received ethical approval from the relevant international and national stakeholders [3, 39], so they have demonstrated an intention and plan to conduct research that complies with ethical principles in relation to informed consent, favourable risk-benefit ratio, social value, respect for persons and communities [22]. The diversity with which these principles are interpreted 
and enacted in individual studies is clearly complicated by the extreme challenges faced when conducting health research in an outbreak setting.

In the following sections, we describe three interrelated themes that emerged from our analysis as capturing activities as essential elements that constitute 'effective' CE. The three interrelated themes are: (1) Communication towards building collaborative relationships; (2) Producing contextual knowledge; and (3) Learning lessons over time. In addition to interplay between these themes, there is also variation from the influence of other elements of the research, including trial design, human resources, and logistics management. This interpretive framework helps us to paint a picture of the on-the-ground experience, lifting out nuance and details that might otherwise be lost.

\section{Three CE themes}

Theme 1: communication towards building collaborative relationships The need for accurate and culturally sensitive communication with relevant community stakeholders about a trial is widely recognised as a critical preliminary step in the research process $[11,51]$. As is well described in the literature, communication can serve a range of purposes, from more 'one-way' or outreach forms of communication to more 'bi-directional' or participatory forms-supporting learning and consultation, for example.

In addition, as for $\mathrm{CE}$ as a whole, some purposes in communicating may have more intrinsic than instrumental value, although these may be difficult to tease apart. An example of an intrinsic value (or 'good in itself') would be communication that realises respect for individuals or communities. Reynolds and Sariola call this intrinsic value the "moral ideals of scientific research" ([48], p. 257). This is relevant to the role of listening to, understanding and responding to a variety of conceptualisations of disease and health responses to it, which are often peppered with mistrust, fear and confusion in the context of an infectious disease outbreak. Communication then has instrumental value in its ability to clarify messages, tackle mistrust and generate support for research, but is also intrinsic in allowing the lived experiences of stakeholders to be respected, heard, recognised and integrated into the functioning of the research.

Unpacking the explicit and implicit aims of communication methods - particularly in the context of setting up a new trial, perhaps in a research-naïve community - can lay the groundwork for continued communication strategies that are cognisant of their multiple effects. While broadcasted communication can be useful in getting information to a large audience, there are challenges in using this approach to spread 'correct' messages or address rumours and misinformation if it is not accompanied by multidirectional, bottom up, interpersonal forms of communication, allowing for sources, justifications and ontologies of these rumours and misinformation to emerge and be understood [24, 28].

A helpful interpretation of this general approach to communication in the context of outbreak research is given by Kennedy et al. who reframe 'one-way' communication as a more instrumental process, for example around the 'dispelling' of myths and misconceptions ([33], p. 52); and 'bi-directional' forms as more intrinsic, revealing concerns about health interventions "stemming from histories of mistrust, rather than simply being misunderstandings" ([26], p. 8). Instrumental aims might include increasing recruitment alongside the dispelling of myths (perhaps also to improve recruitment and retention) but falls short of calls in the research ethics literature for collaborative partnerships with community, health provider and policy stakeholders (at national and local levels) to be a basic building block of ethical practice [21].

Trial reports make it clear that both one-way (outreach) and bi-directional (collaborative) communication strategies were used in practice. One core and seemingly obvious reason for paying more attention to 'outreach' is the number and distribution of potential participants in a trial. The three trials in Sierra Leone and Liberia that involved large numbers of healthy volunteers across wide geographic areas (Ebola ca Suffit, Ebovac Salone, and PREVAIL) paid more attention to outreach than others, and also built in bi-directional communication processes. In contrast, the trials recruiting volunteers from health workers (STRIVE) and patient or survivor populations (JIKI and Ebola Tx) largely reported on interpersonal communication strategies, at patient/patient group and policy stakeholder levels, including - in the case of Ebola $\mathrm{Tx}$ - an association of survivors to secure plasma donors needed for the intervention. Throughout the accounts in this section, differences in the 'community' to be engaged related to the nature of the trial and was reflected in chosen approaches.

Reflecting the variation in CE approaches with that of trial design, all teams recognised the importance of a wide range of communication activities, from outreach to bidirectional and interpersonal. For example, the PREVAIL team described using multiple communication strategies in different ways to achieve "an exceptionally high participant retention rate (97\%)", despite numerous logistical and operational challenges 
([8], p. 50). Throughout the following sections, we provide examples of different communication activities and the authors' reflections on these in terms of 'effectiveness' or satisfying aims.

\section{Broad outreach activities}

Across the vaccine trials in the core literature, communication was regularly enacted as forms of outreach or 'broadcast', for example through "the local media, regular press conferences and distribution of flyers, preparation and airing of jingles and songs on television and radio, and distribution of text messages" ([33], p. 52). One large communication campaign was the "Ebola Big Idea of the Week' campaign run by the CDC. It involved approximately 80 radio, television, and print journalists from Sierra Leone trained by experts to develop one critical idea every week through culturally sensitive messaging [6]. For PREVAIL, the strategic plan for 'social mobilisation' included outreach elements of branding, print and broadcast media communication through distributing flyers, television, radio and mobile phone messaging [8]. The aim of these mechanisms was getting 'facts' to a wide audience in order to clarify, support and inform through a largely one-way process, but also to be part of a wider approach to targeting myths, rumour and suspicions.

Both of the treatment trials included in the core literature describe a strong focus on $\mathrm{CE}$ with patients and government health authorities responsible for public health programming, including service delivery and epidemic control measures in the surrounding communities. The Ebola Tx treatment trial, which involved transfusion of plasma from EBV donors, had a particularly strong focus on engagement with the EBV Survivors Association, whose cooperation and support underpinned feasibility of the intervention. Reports from the JIKI treatment trial in Guinea gave particularly clear accounts of the challenges and processes for implementation of the trial at field level. At the first site, a treatment centre in Guéckédou, Perez et al. [47] describe that CE was understood as "essential to ensuring the appropriate implementation and progression of the trial" (ibid. p. 7). The challenges faced for CE included the mistrust of governments and Western humanitarian agencies, and rumours about EVD. In response, communication about the trial objectives and implementation was seen as needing messages that "were adapted to context, minimised fear, and managed inappropriate expectations". A central element of this CE response was the setting up of a Community Advisory Board (CAB), comprising local leaders, women's organisations, youth groups, religious leaders and village elders (ibid. p. 22). However, the success of instituting a $C A B$ is difficult to assess from the research articles. Other closely related mechanisms to CABs were also used. For example, the Ebovac Salone research team also set up a Participant Advisory Group (PAG) in the initial stages of their formative research and their CE strategy involved a wide range of community stakeholders "from elected and traditional leaders to individual households" ([25], p. 4). $\mathrm{CE}$ was designed in this respect to link with on-theground organisations and proved valuable for implementing research in an emergency ([44], p. 4). However, CABs are potentially more reflective of collaborative partnerships than some other forms of communication and engagement given the positions of authority that community members have on them. The PAG may appear more limited in scope but may provide meaningful participant advisory in a limited time period of a trial.

\section{Interpersonal and key stakeholder communication}

All trials included elements of communication targeting individuals or specific groupings of potential participants or 'influencers'. For the vaccine trials, a study involving health workers in Sierra Leone used a designated hot line and information sharing meetings for potential participants and the wider health workforce. The PREVAIL team highlight interpersonal, local, face-to-face communication as a critical strategy. One such strategy was employing 25 Liberians living in the main town in the trial area as 'participant trackers' to engage in ongoing conversations about daily experiences of being in the trial. The feedback about these 'participant trackers' was that crucial information was collected in determining the names of participants (in the communities some residents were only known by nicknames), their locations (using descriptions if there were no street names and relying on family and friends to have knowledge of their whereabouts), and the ability to contact them (e.g. a phone number of a community store) [8]. While Browne et al. do not comment on the potential for these kinds of strategies to be intrusive or coercive, they do see 'effectiveness' in the high participant retention, and the success of strategies such as home visits in avoiding any overt opposition and dissatisfaction. Another interpersonal communication strategy reported was supporting members of the clinical team (nurses and clinical monitors) to take on communication roles for the trial as part of their everyday interactions with participants and others, by reinforcing messages and tackling stigma, myths and rumours ([8], p. 52).

As a community-based vaccine trial, EBOVAC-Salone set up a dedicated Community Liaison team that worked closely alongside trial researchers and a social science team throughout the study. The main role of the Community Liaison team was to manage community messaging and communication, and conditions for participation and informed consent, through community 
and household-level meetings alongside community leaders (Fayia [29], p. 37).

The literature emphasizes how closely the trial, community liaison and social science teams worked together, aiming to inform "research-driven communication strategies" ([24], p. 5). For example, they describe their process of holding weekly meetings where findings and feedback could be reported, synthesised and acted upon. This approach (which overlaps with an aspect of CE discussed later - incorporating findings and feedback loops) allows for a communication strategy that is not only instrumentally effective in managing rumours and myths and sharing accurate information but creates a platform for daily experiences to be voiced and incorporated into the trial's work. Mooney et al. cite an example where a rumour that the vaccine trial was bringing Ebola back to a community was identified by social scientists and responded to by the community liaison team, who visited the local marketplace known to be the place where the rumour had originated. They were then able to engage with concerned citizens directly, "with the support of pre-briefed local stakeholders" ([44], p. 439).

The team at STRIVE (a Phase III vaccine trial involving front line health workers in Sierra Leone) also highlight communication as important in building community trust and mitigating rumours and misinformation [11]. The main rationale described for their engagement was to encourage recruitment, protect participants, and get buy-in at higher levels of national leadership [12]. The communication team, with the help of social mobilisation experts (SMEs) [20], were responsible for ensuring voluntary, informed participation [11]. The approach to participation was based on a tailored social ecology model "to identify and reach specific spheres that influence a potential participant's decision-making" (ibid. S. 41). This model is a way of showing how an issue can be influenced at multiple societal levels and was used to reach people from different spheres with different norms, influences, perceptions, and support, as well as to foster understanding particular to each sphere (ibid. S. 41). In this trial, informal communication was used instrumentally, where investing in communication training for all staff was part of creating a facilitating environment for conversations seen as at least as constructive as the formal communication efforts (ibid. S. 46).

Theme 2: producing contextual knowledge formative social science research Formative research is "the process by which researchers or public health practitioners define a community of interest, determine how to access that community, and describe the attributes of the community that are relevant to a specific public health issue" ([13], p. 2). The use of formative research prior to and for the purpose of informing trial design and implementation is a core part of CE strategy. The experiences of trials conducted during the West Africa EVD outbreak demonstrate this. The work done within the EBOVAC-Salone trial is particularly illustrative of this, as described by Enria et al. [24] as the "real-time social science research". A locally-recruited social science research team operated alongside a locally-recruited community liaison team, and overall clinical research team, with formative social science research playing a crucial role [26]. The social science team included four research assistants from Kambia District where the trial was located, a data analyst and a transcriber, with supervision from an LSHT $M$ social scientist (ibid.). They used a range of traditional qualitative research methods, including interviews and ethnographic observation in local social areas and trial clinics in the three months prior to the trial clinical work. This 'stage 1' research and a second support 'stage 2' continued alongside the clinical part of the trial. A critical aspect of the EBOVAC-Salone team's use of social science research is that it went past the formative phase and continued throughout the trial's CE process.

In terms of the types of social science methods employed, for the Ebola treatment trial with convalescent plasma, an anthropological pre-trial assessment was carried out to better understand the context, acceptability of EVD therapies, stakeholders expectations ([18], p. 648) as well as volunteer motivations, concerns, and their underlying influences [49]. It is unclear who conducted the assessment or whether results were published as a separate set of findings; however, the findings demonstrated the importance of stakeholder communication "to understand and follow up what people thought, felt, perceived, and how they acted during the EVD outbreak and consequential health control activities" ([18], p. 648). This led to discussions about how stakeholders, particularly members of the survivors association that was set up, could be involved in the study. Another example of a reflection of social science methods is the systematic literature review by Johnson and Vindrola-Padros, "Rapid qualitative research methods during complex health emergencies" [32] and subsequent rapid review methodology articles relating to COVID-19 pandemic research [54, 55]. Rapid qualitative methods were effective in understanding community resilience for public health emergencies and planning CE based on this.

Other social science research concentrated on specific aspects of community perceptions and behaviours that affected the public health response. This included motivations for volunteering in research studies (Fayia [29]); the reception to the "bushmeat ban" and public health messaging about the risks of consuming bushmeat [7]; to wider questions about the connection to understandings of citizenship and belonging through encounters with biomedicine [23]. 
A number of questions arise in the use of formative research to understand context during epidemics for future consideration. Can anthropological research be done in such a short period, especially in a researchnaïve area? Who are the anthropologists doing this research? What if the results of their research suggest an unsuitable setting for clinical research? Could the entire trial be relocated given the extreme logistical and time constraints? In other words, what are the specific intentions and aims of the formative research - to prime the setting or to ask open-ended questions about the ethical, social, cultural and historical feasibility of conducting trials in the setting? These studies have shown that these broader questions have largely gone unanswered and will need to be considered for future formative research in outbreaks.

Theme 3: learning lessons over time - incorporating findings, creating feedback loops and building a sustaining legacy To learn lessons means relying on collaborative partnerships so that the various stakeholder ideas and recommendations are taken seriously and built into plans going forwards. The feedback of this information often takes place outside formal structures such as CABs. Knowing and understanding whose feedback is getting incorporated and why is an important step in mapping out the effectiveness of CE strategy. Browne, et al. [8] note how PREVAIL nurses responded to participants' experiences of stigma by reiterating messages relayed by the Social Mobilisation Experts (SMEs) as part of their broader strategy. Community health workers (CHWs) are also highlighted by Miller et al. [40] as playing an important role during the EVD outbreak and remained active in their communities after. This multiplicity of roles and the use of different stakeholder channels for reinforcement of messaging is an on-the-ground reality difficult to capture in descriptions of formal communication structures and strategies.

The PREVAIL trial's fourth social mobilisation strategy pillar was monitoring and evaluating mobilisation activities, including "joint review mechanisms that incorporated community leaders, diverse community groups, and government partners to ensure output, impact and challenges of the social mobilisation campaign were identified and changes instituted address existing gaps" ([33], p. 53). The trial design was adapted as a result of incorporating feedback. Study protocols are fairly inflexible once finalised, but in cases where it is possible, getting feedback on the study design before it is finalised (usually through formative research) from local stakeholders and community members is essential for including communities in the design of research.

The EBOVAC-Salone recruitment strategy was strongly informed by clinical expertise, conversations with local staff and insights from anthropological research, and thus shaped according to both clinical standards and local perceptions of what a "fair" and "representative" selection process should be: "Given assumptions that access to resources is assumed to be based on "connectocracy", there was the potential that, given the limited number of participants required, people could have assumed that the "big ones" were picking themselves and those they knew" ([24], p. 6). Sierra Leone's history of conflict opened the potential for "participant recruitment to be likened to forced conscription" and added sensitivities for the trial recruitment process (ibid.). Table 3 below outlines the stages of feedback loops.

Compensation and plausible benefit was provided, such as the EBOVAC-Salone trial offering participants compensation for transportation to the clinic but other trials at different locations in the country at that time offered more money and sometimes a mobile phone ([44], p. 439). Some saw the provisions of incentives as a worrying commodification tantamount to "exchanging blood, one's life essence, for money" and generous financial compensation was not necessary to stimulate participation in the trial in Kambia (ibid.). Still, the Liberian trial team assigned dollar amounts appropriate for the PREVAIL trial setting with compensation for inconvenience, which may have contributed to retention: A baseline visit was $\$ 40.00$, follow-up blood draw was $\$ 20.00$, and close out visit was $\$ 150.00$ ([8], p. 53). Building future infrastructure was another way for $\mathrm{CE}$ to have both intrinsic and instrumental value. For example, the formation of the 'Global Emerging Pathogens Consortium' (GET), a civil society group comprised of African academics, scientists, clinician, and civil society as a crisis response network, is an example of an enduring legacy for CE [1].

We have summarised our findings through three themes: (1) Communication towards building collaborative relationships; (2) Producing contextual knowledge; and (3) Learning lessons over time. See Table 4 below for the full list of all papers in this review, divided specifically by the themes and also whether they were general trial or trial-related papers.

Across our review of 59 papers, the core material related exclusively to health research trials during the 2014-2016 West Africa Ebola outbreak in Liberia, Sierra Leone, and Guinea. In addition, even though we included studies from 1990, the majority were from 2015 onward. In some cases, reports of CE practices were limited to a few paragraphs in articles primarily focused on other elements such as study design and reporting results $[18,31,33]$. However, some trial groups authored full-length publications in which community engagement aspects were amongst the main foci of the paper $[11,44]$. 
Table 3 Stages of feedback loops. Based on article by [24]: p. 4

\begin{tabular}{ll}
\hline 1. CE plans feedback & $\begin{array}{l}\text { Social science team feedback to study team on CE plans based on socio-cultural research, local community dynamics } \\
\text { and perceptions of the vaccine trial. }\end{array}$ \\
2. Meetings to discuss issues & $\begin{array}{l}\text { Brought up issues encountered by the trial team/ community liaison staff requiring further research by social science } \\
\text { team (e.g. design of the recruitment strategies). }\end{array}$ \\
$\begin{array}{l}\text { 3. Reporting rumours/ } \\
\text { concerns }\end{array}$ & $\begin{array}{l}\text { The social science team reported on rumours or concerns and communicated these to the community liaison team } \\
\text { anonymously (not to breach confidentiality and to maintain independence of research). }\end{array}$ \\
$\begin{array}{l}\text { 4. Response by community } \\
\text { liaison staff }\end{array}$ & $\begin{array}{l}\text { Following feedback, the community liaison staff brainstormed strategies to respond to concerns and rumours. } \\
\text { Strategies depended on specific issues raised, but usually involved different creative avenues for discussion with } \\
\text { community and reviewing messaging to actively engage, as well as determining who was the best person in the } \\
\text { team to respond and through which channel. }\end{array}$
\end{tabular}

Discussion: Key elements for 'effectiveness' in CE We have reviewed the literature on $\mathrm{CE}$ for health research for infectious disease outbreaks in Sub-Saharan Africa. While there is a large volume of literature documenting $\mathrm{CE}$ activities in infectious disease research settings generally, there are few accounts of effectiveness dimensions of $\mathrm{CE}$. Our review proposes the consideration of three themes by researchers to facilitate the effectiveness of their CE initiatives. After identifying the high-level principles and benchmark documents we looked to the three core areas of literature of ethics, public health response, and outbreak research; then we assessed how these translated to on-the-ground CE.

In the previous sections, we have described three themes that emerged from our analysis as particularly important in informing the effectiveness of CE planned and implemented during health research in outbreaks. Clearly, research design has a crucial influence on the nature of $\mathrm{CE}$ planned, and in particular, the extent to which geographically defined communities might be implicated by the research activity.

We have made a first core argument that communication approaches should be multifaceted and tailored to context, but include elements that build collaborative relationships between partners. A helpful interpretation of this general approach to communication in the context of outbreak research is given by Kennedy [33] who reframes 'one-way' communication as a more reactive process, for example around the dispelling of myths and misconceptions ([33], p. 52), and 'bi-directional' forms as more exploratory, revealing and taking seriously the concerns about health interventions held by communities where the research is situated [26].

The move from 'one-way' forms of communication towards bi-directional communication or even collaborative relationships implies a shift from less to more

Table 4 Literature divided by trials and three themes

\begin{tabular}{|c|c|c|c|}
\hline Ebola trials and trial-related & $\begin{array}{l}\text { 1. Communication Towards } \\
\text { Building Collaborative } \\
\text { Relationships }\end{array}$ & $\begin{array}{l}\text { 2. Producing contextual knowledge: } \\
\text { Formative social science research }\end{array}$ & $\begin{array}{l}\text { 3. Learning lessons over time: } \\
\text { Incorporating findings, creating } \\
\text { feedback loops and building a } \\
\text { sustaining legacy }\end{array}$ \\
\hline $\begin{array}{l}\text { Abramowitz et al. 2018 [2] } \\
\text { Alirol et al. } 2017 \text { [3] } \\
\text { Caleo et al. } 2018 \text { [10] } \\
\text { Coltart et al. } 2017 \text { [15] } \\
\text { Dean et al. } 2016 \text { [17] } \\
\text { Emanuel et al. } 2004 \\
\text { Folayan et al. } 2015 \text { [30] } \\
\text { Keusch et al, } 2017 \text { [34] } \\
\text { Marsh et al, } 2008 \text { [38] } \\
\text { Marchant \& Lees, 2019 [37] } \\
\text { Mehand et al. 2018 [39] } \\
\text { Mills et al. 2005 [41] } \\
\text { Olu et al. 2016 [45] } \\
\text { Pedi et al. 2017 [46] } \\
\text { Slevin et al. 2008 [50] } \\
\text { Tindana, 2007 [52] } \\
\text { UNAIDS, AVAC. 2011 [53] } \\
\text { Wellcome Trust and CIDRAP, 2015 [14] } \\
\text { WHO, 2017 [59] } \\
\text { WHO, 2016 [57] } \\
\text { Wilkinson et al. 2017 [58] }\end{array}$ & $\begin{array}{l}\text { Bedrosian et al. } 2016 \text { [6] } \\
\text { Browne et al. } 2018 \text { [8] } \\
\text { Callis et al. } 2018 \text { [11] } \\
\text { Carter et al. } 2018 \text { [12] } \\
\text { Ebola ça suffit consortium } 2015 \text { [20] } \\
\text { Emanuel et al. } 2005 \text { [21] } \\
\text { Enria et al. } 2016 \text { [24] } \\
\text { Enria et al. 2016a [25] } \\
\text { Enria et al. 2016b [26] } \\
\text { Fairhead 2016 [28] } \\
\text { Perez et al. } 2017 \text { [47] } \\
\text { Fayia Tengbeh et al. 2018 Fayia [29] } \\
\text { Kennedy et al. 2016 [33] } \\
\text { Mooney et al. } 2018 \text { [44] } \\
\text { Reynolds \& Sariola 2018 [48] } \\
\text { Spengler et al. 2016 [51] }\end{array}$ & $\begin{array}{l}\text { CDC. } 2013 \text { [13] } \\
\text { Bonwitt et al. } 2018 \text { [7] } \\
\text { Delamou et al. } 2016 \text { [18] } \\
\text { Enria and Lees } 2018 \text { [23] } \\
\text { Enria et al. } 2016 \text { [24] } \\
\text { Fayia Tengbeh et al. } 2018 \text { Fayia [29] } \\
\text { Ronse et al. } 2018 \text { [49] } \\
\text { Johnson \& Vinndrola-Padros, } 2017 \text { [32] }\end{array}$ & $\begin{array}{l}\text { Abayomi et al. } 2016 \text { [1] } \\
\text { Browne, et al. } 2018 \text { [8] } \\
\text { Callis et al. } 2018 \text { [11] } \\
\text { Delamou et al. } 2016 \text { [18] } \\
\text { Enria et al. } 2016 \text { [24] } \\
\text { Henao-Restrepo et al. } 2016 \text { [31] } \\
\text { Kennedy et al. } 2016 \text { [33] } \\
\text { Miller et al. } 2018 \text { [40] } \\
\text { Mooney et al. } 2018 \text { [44] }\end{array}$ \\
\hline
\end{tabular}


participatory forms of $\mathrm{CE}$, as has been commented on elsewhere in this article. Unpacking the different implications of these two (sometimes conflicting) approaches to $\mathrm{CE}$ is important for clarifying and achieving its aims. Whether $\mathrm{CE}$ is undertaken for exploratory or reactive reasons, the question of who benefits is still relevant, as is that of how fairly the benefits are distributed. Reluctance to overburden the public health response team features strongly among researchers and practitioners designing and implementing $\mathrm{CE}$ for research in outbreaks, noting that $\mathrm{CE}$ for a public health response and in support of research may rely on the same teams. Overcoming impediments of mistrust, conflicting perceptions, and misunderstandings of the relationship between research and response are also acknowledged in the literature on $\mathrm{CE}$ for research in outbreaks.

We have made a second argument that social science research-formative and ongoing-is a critical component in guiding the shape and content of CE during an outbreak and ensuring that the collaborative relationships researchers aim to build are well-founded, meaningful and durable. Our third argument then stems from the first two, to highlight the importance of a commitment to learning lessons from on-going experiences during an outbreak, so that research teams can flexibly adapt and sustain the collaborative relationships on which the research enterprise depends. We extend this third argument further, to agree with the authors of the WHO GPP-EP guidelines that in view of long-standing structural inequities that characterise settings in which outbreaks are likely to arise, there should be a long-term commitment to supporting a sustainable legacy for communities.

Our review suggests that good practice in $\mathrm{CE}$ in the context of outbreak research (and potentially for research in general) is underpinned by bi-directional communication, the careful longitudinal incorporation of social science research into planning, and ensuring that structures are in place to support meaningful feedback and adaptation of research practice on the ground. This includes efforts to ensure that $\mathrm{CE}$ has an enduring legacy from research, for the benefit of a widely defined community. Through this scoping review we have found that, while $C E$ research literature documents the activities of $\mathrm{CE}$ conducted in the context of clinical research during disease outbreaks, the next step of deriving the essential elements of meaningful and effective engagement has not been taken and is what makes this scoping review novel. Going forward, the additional work needed in order to further knowledge in assessments of CE will be to consider broader implications of $\mathrm{CE}$ on an aggregate level, taking into consideration the kinds of research - largely qualitative - that may answer some of these questions.
However, we do acknowledge the following limitations. First, we made the decision to limit our research to Sub-Saharan Africa. A comparative global review may prove useful, particularly with the Americas and Asian regions where different outbreaks have taken place recently (Dengue, Zika etc.), inviting varied CE responses. In light of the COVID-19 pandemic, a truly global review for $\mathrm{CE}$ responses would also be very valuable. Second, our review was largely confined to the English language, and only reviewed one paper in French. Further language searches would add to the body of knowledge.

\section{Conclusion}

We have presented our findings from a synthesis of three key themes arising from descriptions of CE strategies and their effectiveness, as essential elements of $\mathrm{CE}$ activities in infectious diseases studies: (1) Communication towards building collaborative relationships; (2) Producing contextual knowledge; and (3) Learning lessons over time. Researchers and their partners implementing $\mathrm{CE}$ programs for health research in epidemics can use these themes to guide improving practice.

Throughout the process of conducting this review (and also confirmed at the ALERRT 2019 Community Engagement Workshop in Senegal), it has become apparent that strengthening $\mathrm{CE}$ is both an art and a process, a philosophy and a science. Achieving both the instrumental aims (effectiveness, strengthening, quality, and impact) and intrinsic aims (respect, recognition, and equality) of $\mathrm{CE}$ requires a deliberative effort through the nexus of relationships, knowledge, and lesson-learning for better listening to and speaking with communities affected by outbreaks of infectious diseases. The importance of documenting and sharing lessons learnt to improve $\mathrm{CE}$ practice remains paramount as current epidemics continue.

We set out to characterise the nature and effectiveness of $C E$ activities in infectious disease research settings in Sub-Saharan Africa. Given the nature of the wider literature on community engagement in research, our findings act to underline their interrelatedness of these themes and their core role in supporting 'effectiveness' across the literature reviewed on CE during the EBV epidemic. There is value in concentrating on these areas in planning $C E$ in similar situations in future. As there were relatively few in-depth accounts of $\mathrm{CE}$ from our literature review, documentation and accounts of $\mathrm{CE}$ used in health research should be prioritised going forward, thus contributing to more thorough trial reporting in the future. A further lesson is the need for more research and analysis on what constitutes effectiveness in $\mathrm{CE}$ in research, and greater transparency in reporting 
around the processes and impacts of CE. A deeper understanding through more comprehensive reporting of the mechanisms of $\mathrm{CE}$ would provide stakeholders with a benchmark for assessing the ethical principles around $\mathrm{CE}$ and offer a tangible, on-the-ground opportunity to enact them.

\section{Supplementary Information}

The online version contains supplementary material available at https://doi. org/10.1186/s12889-021-10348-0.

Additional file 1. Conceptual framework of 3 core themes for effective CE. We show a diagrammatic representation of the nature of and interplay between these three elements, illustrating the way they may work together towards supporting effective CE and providing a 'marker' for community responsiveness. Relevant benchmarks from the 'state-ofthe-art' reports are shown in the diagram, indicating their role in an overall analysis

Additional file 2. Scoping Review Search terms. Search terms of trial search on Scopus and final search across all included databases

Additional file 3. PRISMA Checklist. Preferred Reporting Items for Systematic reviews and Meta-Analyses extension for Scoping Reviews (PRISMA-SCR) Checklist

\section{Abbreviations}

ALERRT: African coaLition for Epidemic Research, Response and Training; CAB: Community advisory board; CERqual: Confidence in the Evidence from Reviews of Qualitative research; CASP: Critical Appraisal Skills Programme; AACODS: Authority, Accuracy, Coverage, Objectivity, Date, Significance; CDC: Centers for Disease Control and Prevention; CE: Community engagement; CHW: Community health workers; CIDRAP: Center for Infectious Disease Research and Policy; ETC: Ebola treatment center; EVD: Ebola virus disease; HIV/AIDs: Human immunodeficiency virus/acquired immunodeficiency syndrome; LMI: Low- and middle-income countries; MNCH: Maternal, newborn, and child health services; PRISMA: Reporting Items for Systematic Reviews and Meta-Analyses; RCT: Randomised controlled trial; SME: Social mobilisation expert; WHO: World Health Organization

\section{Acknowledgements}

We would like to thank the participants of the ALERRT 2019 Community Engagement Workshop in Senegal.

\section{Authors' information (optional)}

$\mathrm{n} / \mathrm{a}$

\section{Authors' contributions}

MV and SV searched the literature, analysed the results, and wrote the manuscript with oversight throughout from VM. VM, SL, MM and SK provided further analysis of results. SL conceived the study and both SL and VM provided editorial input. All contributors read and approved the final version. Our funding body had no role in the design of the study and collection, analysis, and interpretation of data or in writing the manuscript.

\section{Funding}

This literature review was funded by 'ALERRT', which is part of the EDCTP2 Programme supported by the European Union under grant agreement RIA2016E-1612. ALERRT is also supported by the United Kingdom National Institute for Health Research.

\section{Availability of data and materials}

No additional data are available. The Review Protocol is published online at Prospero: Registration number CRD42018112501 and available at https:// www.crd.york.ac.uk/PROSPERO

Ethics approval and consent to participate $\mathrm{n} / \mathrm{a}$

\section{Consent for publication}

$\mathrm{n} / \mathrm{a}$

\section{Competing interests}

None declared.

\section{Author details}

1Oxford Vaccine Group \& Oxford Martin School, University of Oxford, 34 Broad St, Oxford OX1 2BD, UK. ${ }^{2}$ School of Public Health, University of the Western Cape, Robert Sobukwe Road, Bellville 7535, Republic of South Africa. ${ }^{3}$ Department of Global Health and Development, London School of Hygiene \& Tropical Medicine, London, UK. ${ }^{4}$ Department of Public Health, University of Yaounde I, Rue Melen, Yaounde, Cameroon. ${ }^{5}$ KEMRI Wellcome Trust Programme, Nairobi, Kenya. ${ }^{6}$ Centre for Tropical Medicine and Global Health, NDM, Oxford University, Oxford, UK. ' Kenya Medical Research Institute -

Wellcome Trust Research Programme, Kilifi, Kenya.

Received: 29 December 2019 Accepted: 27 January 2021

Published online: 01 April 2021

\section{References}

1. Abayomi A, Gevao S, Conton B, Deblasio P, Katz R. African civil society initiatives to drive a biobanking, biosecurity and infrastructure development agenda in the wake of the west African Ebola outbreak. Pan Afr Med J. 2016;24 https://doi.org/10.11604/pamj.2016.24.270.8429.

2. Abramowitz SA, Hipgrave DB, Witchard A, Heymann DL. Lessons from the West Africa Ebola epidemic: A systematic review of epidemiological and social and behavioral science research priorities. J Infect Dis. 2018; https:// doi.org/10.1093/infdis/jiy387.

3. Alirol E, Kuesel AC, Guraiib MM, de la Fuente-Núñez V, Saxena A, Gomes MF. Ethics review of studies during public health emergencies - the experience of the $\mathrm{WHO}$ ethics review committee during the Ebola virus disease epidemic. BMC Med Ethics. 2017;18(1):43 https://doi.org/10.1186/s12910017-0201-1.

4. Arksey H, O'Malley L. Scoping studies: towards a methodological framework. Int J Soc Res Methodol. 2005;8(1):19-32 https://doi.org/10.1080/ 1364557032000119616.

5. Arnstein SR. A ladder of citizen participation. J Am Inst Plann. 1969;35(4): 216-24 https://doi.org/10.1080/01944366908977225.

6. Bedrosian SR, Young CE, Smith LA, Cox JD, Manning C, Pechta L, Telfer JL, et al. Lessons of risk communication and health promotion - West Africa and United States. Mmwr-Morbid Mortality Weekly Report. 2016;65(3):68-74.

7. Bonwitt J, Dawson M, Kandeh M, Ansumana R, Sahr F, Brown H, Kelly AH. Unintended consequences of the 'Bushmeat ban' in West Africa during the 2013-2016 Ebola virus disease epidemic. Soc Sci Med. 2018;200(March):16673 https://doi.org/10.1016/J.SOCSCIMED.2017.12.028.

8. Browne S, Carter T, Eckes R, Grandits G, Johnson M, Moore I, McNay L. A review of strategies used to retain participants in clinical research during an infectious disease outbreak: the PREVAIL I Ebola vaccine trial experience. Contemp Clin Trials Commun. 2018;11(May):50-4 https://doi.org/10.1016/j. conctc.2018.06.004.

9. Brunton G, Thomas J, O'Mara-Eves A, Jamal F, Oliver S, Kavanagh J. Narratives of community engagement: A systematic review-derived conceptual framework for public health interventions. BMC Public Health. 2017;17(1):944 https://doi.org/10.1186/s12889-017-4958-4.

10. Caleo G, Duncombe J, Jephcott F, Lokuge K, Mills C, Looijen E, Theoharaki F, et al. The factors affecting household transmission dynamics and community compliance with Ebola control measures: A mixed-methods study in a Rural Village in Sierra Leone. BMC Public Health. 2018;18(1) https://doi.org/10.1186/s12889-018-5158-6.

11. Callis A, Carter VM, Ramakrishnan A, Albert AP, Conteh L, Barrie AA, Fahnbulleh $L$, et al. Lessons learned in clinical trial communication during an Ebola outbreak: the implementation of STRIVE. J Infect Dis. 2018;217:S407 https://doi.org/10.1093/infdis/jix558.

12. Carter RJ, Idriss A, Widdowson M-A, Samai M, Schrag SJ, Legardy-Williams JK, Estivariz CF, et al. Implementing a Multisite Clinical Trial in the Midst of an Ebola Outbreak: Lessons Learned From the Sierra Leone Trial to Introduce a Vaccine Against Ebola. J Infect Dis. 2018;217(suppl_1):S16-23. https://doi.org/10.1093/infdis/jix657.

13. Centers for Disease Control and Prevention. 2013. "Handbook of Health Survey Methods." 
14. CIDRAP and the Wellcome Trust. 2015. "Recommendations for Accelerating the Development of Ebola Vaccines." http://www.cidrap.umn.edu/ recommendations-accelerating-development-ebola-vaccines-0.

15. Coltart CEM, Lindsey B, Ghinai I, Johnson AM, Heymann DL. The Ebola outbreak, 2013-2016: old lessons for new epidemics. Philos Trans R Soc B Biol Sci. 2017;372(1721):20160297 https://doi.org/10.1098/rstb.2016.0297.

16. Critical Appraisal Skills Programme. Home - CASP - critical appraisal skills Programme. CASP Syst Rev Checklist. 2018;2018 https://casp-uk.net/. Accessed 20 June 2019.

17. Dean L, Page S, Hawkins K, Stothard R, Thomson R, Wanji S, Gyapong M, Anagbogu I, Molyneux D, Theobald S. Tailoring mass drug administration to context: implementation research is critical in achieving equitable Progress in the control and elimination of Helminth neglected tropical diseases in sub-Saharan Africa. Int Health. 2016;8(4):233-4 https://doi.org/10.1093/ inthealth/ihw031.

18. Delamou A, Haba NY, Mari-Saez A, Gallian P, Ronse M, Jacobs J, Camara BS, et al. Organizing the donation of convalescent plasma for a therapeutic clinical trial on Ebola virus disease: the experience in Guinea. Am J Trop Med Hyg. 2016;95(3):647-53 https://doi.org/10.4269/ajtmh.15-0890.

19. Dickert N, Sugarman J. Ethical goals of community consultation in research. Am J Public Health. 2005. https://doi.org/10.2105/AJPH.2004.058933.

20. Ebola ça suffit ring vaccination trial consortium. The ring vaccination trial: $A$ novel cluster randomised controlled trial design to evaluate vaccine efficacy and effectiveness during outbreaks, with special reference to Ebola. BMJ (Clinical Research Ed). 2015;351(July):h3740 https://doi.org/10.1136/bmj.h3740.

21. Emanuel EJ, Doumbo OK, Hurst SA, Plowe CV, Wellems TE, Diallo DA. Community permission for medical research in developing countries. Clin Infect Dis. 2005;41(2):255-9 https://doi.org/10.1086/430707.

22. Emanuel EJ, Wendler D, Killen J, Grady C. What Makes Clinical Research in Developing Countries Ethical? The Benchmarks of Ethical Research. J Infect Dis. 2004;189(5):930-7. https://doi.org/10.1086/381709.

23. Enria L, Lees S. Citizens, dependents, sons of the soil. Med Anthropology Theory. 2018;5(4):30-55.

24. Enria L, Smout EM, Watson-Jones D, Leigh B, Larson HJ, Mooney T, Lees S, Greenwood B. Implementing a novel community engagement system during a clinical trial of a candidate Ebola vaccine within an outbreak setting. Int J Infect Dis. 2016;45:191 https://doi.org/10.1016/j. ijid.2016.02.444.

25. Enria L, Lees S, Smout E, Mooney T, Tengbeh AF, Leigh B, Greenwood B, Watson-Jones $\mathrm{D}$, Larson $\mathrm{H}$. Power, fairness and trust: understanding and engaging with vaccine trial participants and communities in the setting up the EBOVAC-Salone vaccine trial in Sierra Leone. BMC Public Health. 2016a; 16(1):1-10 https://doi.org/10.1186/s12889-016-3799-x.

26. Enria L, Lees S, Smout E, Mooney T, Tengbeh AF, Leigh B, Greenwood B, Watson-Jones D, Larson $\mathrm{H}$. Power, fairness and trust: understanding and engaging with vaccine trial participants and communities in the setting up the EBOVAC-Salone vaccine trial in Sierra Leone. BMC Public Health. 2016b; 16(1):1-10 https://doi.org/10.1186/s12889-016-3799-x.

27. Fairhead J. The Significance of Death, Funerals, and the after-Life in EbolaHit Sierra Leone, Guinea and Liberia: Anthropological Insights into Infection and Social Resistance; 2014. p. 5.

28. Fairhead J. Understanding social resistance to the Ebola response in the Forest region of the Republic of Guinea: an anthropological perspective. Afr Stud Rev. 2016;59(03):7-31 https://doi.org/10.1017/asr.2016.87.

29. Tengbeh F, Angus LE, Smout E, Mooney T, Callaghan M, Ishola D, Leigh B, et al. 'We are the heroes because we are ready to die for this country'; participants' decision-making and grounded ethics in an Ebola vaccine clinical trial. Soc Sci Med. 2018;203:35-42 https://doi.org/10.1016/j. socscimed.2018.03.008.

30. Folayan MO, Brown B, Haire B, Yakubu A, Peterson K, Tegli J. Stakeholders' engagement with Ebola therapy research in resource limited settings. BMC Infect Dis. 2015;15(1):242 https://doi.org/10.1186/s12879-015-0950-8.

31. Henao-Restrepo AM, Preziosi M-P, Wood D, Moorthy V, Kieny MP. On a path to accelerate access to Ebola vaccines: the WHO's Research and Development efforts during the 2014-2016 Ebola epidemic in West Africa. Curr Opin Virol. 2016;17(April):138-44 https://doi.org/10.1016/j.coviro.2016. 03.008.

32. Johnson GA, Vindrola-Padros C. Rapid qualitative research methods during complex health emergencies: A systematic review of the literature. Soc Sci Med. 2017;189(September):63-75 https://doi.org/10.1016/j.socscimed.2017. 07.029 .
33. Kennedy SB, Neaton JD, Clifford Lane H, Kieh MWS, Massaquoi MBF, Touchette NA, Nason MC, et al. Implementation of an Ebola virus disease vaccine clinical trial during the Ebola epidemic in Liberia: design, procedures, and challenges. Clin Trials. 2016;13(1):49-56 https://doi.org/10. $1177 / 1740774515621037$.

34. Keusch G, McAdam K, Cuff P, Mancher M, Busta ER, editors. Integrating clinical research into epidemic response. Washington, D.C.: National Academies Press; 2017. https://doi.org/10.17226/24739

35. Landford, Terri. n.d. "UC Library Guides: Grey Literature in Health: Appraisal (The AACODS Checklist)." https://canberra.libguides.com/c.php?g=59934 $8 \& p=4148869$. Accessed 1 Nov 2019

36. Lewin S, Glenton C, Munthe-Kaas H, Carlsen B, Colvin CJ, Gülmezoglu M, Noyes J, Booth A, Garside R, Rashidian A. Using qualitative evidence in decision making for health and social interventions: an approach to assess confidence in findings from qualitative evidence syntheses (GRADE-CERQual). PLoS Med. 2015;12(10):e1001895 https://doi.org/10.1371/journal.pmed.1001895.

37. Marchant M, Lees S. Understanding the role of community engagement in medical research | ALERRT. In: Global Emerging Pathogens Treatment Consortium (GET) Newsletter; 2019. https://www.alerrt.global/content/ understanding-role-community-engagement-medical-research.

38. Marsh V, Kamuya D, Rowa Y, Gikonyo C, Molyneux S. Beginning community engagement at a busy biomedical research Programme: experiences from the KEMRI CGMRC-Wellcome Trust research Programme, Kilifi, Kenya. Soc Sci Med. 2008;67(5):721-33.

39. Mehand MS, Al-Shorbaji F, Millett P, Murgue B. The WHO R\&D blueprint: 2018 review of emerging infectious diseases requiring urgent Research and Development efforts. Antivir Res. 2018;159(September):63-7 https://doi.org/ 10.1016/j.antiviral.2018.09.009.

40. Miller NP, Milsom P, Johnson G, Bedford J, Kapeu AS, Diallo AO, Hassen K, et al. Community health workers during the Ebola outbreak in Guinea, Liberia, and Sierra Leone. J Glob Health. 2018;8(2):20601 https://doi.org/10. 7189/jogh-08-020601.

41. Mills E, Rachlis B, Wu P, Wong E, Wilson K, Singh S. Media Reporting of Tenofovir Trials in Cambodia and Cameroon. BMC Int Health Hum Rights. 2005;5:6. https://doi.org/10.1186/1472-698X-5-6.

42. Molyneux S, Bull S. Consent and community engagement in diverse research contexts: reviewing and developing research and practice. J Empirical Res Hum Res Ethics. 2013;8(4):1-18 https://doi.org/10.1525/jer.2013.8.4.1.

43. Molyneux S, Geissler PW. Ethics and the ethnography of medical research in Africa. Soc Sci Med. 2008;67(5):685-95 https://doi.org/10.1016/j.socscimed. 2008.02.023.

44. Mooney T, Smout E, Leigh B, Greenwood B, Enria L, Ishola D, Manno D, Samai M, Douoguih M, Watson-Jones D. EBOVAC-Salone: lessons learned from implementing an Ebola vaccine trial in an Ebola-affected country. Clin Trials. 2018;15(5):436-43 https://doi.org/10.1177/ 1740774518780678.

45. Olu OO, Lamunu M, Nanyunja M, Dafae F, Samba T, Sempiira N, Kuti-George $\mathrm{F}$, et al. Contact tracing during an outbreak of Ebola virus disease in the Western area districts of Sierra Leone: lessons for future Ebola outbreak response. Front Public Health. 2016;4(June):130 https://doi.org/10.3389/ fpubh.2016.00130.

46. Pedi D, Gillespie A, Bedson J, Jalloh MF, Jalloh MB, Kamara A, Bertram K, Owen $\mathrm{K}$, Jalloh MA, Conte L. The development of standard operating procedures for social mobilization and community engagement in Sierra Leone during the West Africa Ebola outbreak of 2014-2015. J Health Commun. 2017;22(0):39-50 https://doi.org/10.1080/10810730.2016.1212130.

47. Perez SC, Folkesson E, Anglaret X, Beavogui A-HH, Berbain E, Camara A-MM, Depoortere $E_{\text {, et }}$ al. Challenges in preparing and implementing a clinical trial at field level in an Ebola emergency: A case study in Guinea, West Africa. PLoS Negl Trop Dis. 2017;11(6):e0005545 https://doi.org/10.1371/ journal.pntd.0005545.

48. Reynolds $L$, Sariola $S$. The ethics and politics of community engagement in Global Health research. Crit Public Health. 2018;28(3):257-68 https://doi.org/ 10.1080/09581596.2018.1449598.

49. Ronse M, Sáez AM, Gryseels C, Bannister-Tyrrell M, Delamou A, Guillard A, Briki $M$, et al. What motivates Ebola survivors to donate plasma during an emergency clinical trial? The case of Ebola-Tx in Guinea. PLoS Negl Trop Dis. 2018;12(10):e0006885 https://doi.org/10.1371/journal.pntd.0006885.

50. Slevin K, Ukpong M, Heise L. Community engagement in HIV prevention trials: evolution of the field and opportunities for growth. Microbicides Dev Programme. aids2031 Science and Technology Working Papers. 2008. 
51. Spengler JR, Ervin ED, Towner JS, Rollin PE, Nichol ST. Perspectives on West Africa Ebola virus disease outbreak, 2013-2016. Emerg Infect Dis. 2016;22(6): 956-63 https://doi.org/10.3201/eid2206.160021.

52. Tindana PO, Singh JA, Tracy CS, Upshur REG, Daar AS, Singer PA, Frohlich J, Lavery JV. Grand challenges in Global Health: community engagement in research in developing countries. PLoS Med. 2007; https://doi.org/10.1371/ journal.pmed.0040273. Public Library of Science.

53. UNAIDS, AVAC. Good participatory practice: guidelines for biomedical HIV prevention trials. Geneva: UNAIDS; 2011. https://doi.org/JC1853E

54. Vindrola-Padros C, Andrews L, Dowrick A, Djellouli N, Fillmore H, Gonzalez $E B$, Javadi $D$, et al. Perceptions and experiences of healthcare workers during the COVID-19 pandemic in the UK. BMJ Open. 2020a;10(11):e040503 https://doi.org/10.1136/BMJOPEN-2020-040503.

55. Vindrola-Padros C, Chisnall G, Cooper S, Dowrick A, Djellouli N, Symmons SM, Martin S, et al. Carrying Out Rapid Qualitative Research During a Pandemic: Emerging Lessons From COVID-19. Qual Health Res. 2020b: $104973232095152 \mathrm{https}: / /$ doi.org/10.1177/1049732320951526.

56. WHO. Emerging diseases: World Health Organization; n.d. http://www.who. int/topics/emerging_diseases/en/. Accessed 1 Feb 2016

57. WHO. 2016. "Good Participatory Practice Guidelines for Trials of Emerging (and Re-emerging) Pathogens That Are Likely to Cause Severe Outbreaks in the near Future and for Which Few or No Medical Countermeasures Exist (GPP-EP) : Outcome Document of the Consultative Pr." http://www.who.int/ blueprint/what/norms-standards/GPP-EPP-December2016.pdf. Accessed 20 June 2019.

58. Wilkinson A, Parker M, Martineau F, Leach M. Engaging 'Communities': Anthropological Insights from the West African Ebola Epidemic. Philos Trans R Soc Lond Ser B Biol Sci. 2017;372(1721):20160305. https://doi.org/10.1098/ rstb.2016.0305. Accessed 20 June 2019.

59. World Health Organization. WHO Community engagement framework for quality, people-Centred and resilient health services: WHO. World Health Organization; 2017. https://apps.who.int/iris/handle/10665/259280

\section{Publisher's Note}

Springer Nature remains neutral with regard to jurisdictional claims in published maps and institutional affiliations.

Ready to submit your research? Choose BMC and benefit from:

- fast, convenient online submission

- thorough peer review by experienced researchers in your field

- rapid publication on acceptance

- support for research data, including large and complex data types

- gold Open Access which fosters wider collaboration and increased citations

- maximum visibility for your research: over $100 \mathrm{M}$ website views per year

At $\mathrm{BMC}$, research is always in progress.

Learn more biomedcentral.com/submissions 